\title{
A mensuração do Produto Interno Bruto do agronegócio de Mato Grosso do Sul
}

\section{The measurement of the Gross Domestic Product of the agribusiness of Mato Grosso do Sul}

\author{
Daniel Massen Frainer ${ }^{1}$, Celso Correia de Souza², José Francisco dos Reis Neto², \\ Raul Asseff Castelão ${ }^{2 *}$ e Michelle da Rosa \\ 1 Universidade Estadual do Mato Grosso do Sul, Brasil \\ 2 Universidade Anhanguera Uniderp, Campo Grande (MS), Brasil \\ ( ${ }^{\star} E$-mail: raulassefcastelao@gmail.com) \\ http://dx.doi.org/10.19084/RCA18159
}

Recebido/received: 2018.05.27

Recebido em versão revista/received in revised form: 2018.07 .19

Aceite/accepted: 2018.07.28

\section{R E S U M O}

Este artigo procura mensurar o PIB do estado de Mato Grosso do Sul e caracterizar o agronegócio na economia do estado e de seus agregados na economia regional, para o ano de 2012. Neste cálculo deve ser considerada a contribuição de cada elo da economia dentro da cadeia produtiva do agronegócio do estado e suas relações de compras e vendas com outros setores. O modelo de insumo-produto constitui-se como ferramenta importante para dimensionar, com maior grau de detalhamento, as cadeias produtivas e o agregado das atividades constituintes do agronegócio. A metodologia e os dados utilizados baseiam-se em diversas fontes secundárias onde foi estimada uma matriz de insumo-produto regional onde foram compilados os valores adicionados a preços de consumidor, além da estrutura dos agregados como: insumos, agropecuária, agroindústria e distribuição. Constatou-se o agronegócio participa com cerca de 37\% do PIB da economia do estado em 2012, onde os setores com maior participação relativa seriam os agregados de distribuição e de agropecuária.

Palavras-chave: Desenvolvimento regional, Insumo-produto, Decisão política.

\section{A B S T R A C T}

This article seeks to measure the GDP of the state of Mato Grosso do Sul and characterize the agribusiness in the state's economy and their aggregates in the regional economy, for the year 2012. This calculation considered should be the contribution of each link in the economy within the productive chain of the state of agribusiness and its purchasing and sales relationships with other sectors. The input-output model constitutes an important tool to scale, with a higher degree of detail, the production chains and the aggregate of the constituent activities of agribusiness. The methodology and the data used based on various secondary sources where a regional input-output matrix where the value added to the consumer prices compiled and estimated, in addition to the aggregate structure as inputs, agriculture, agribusiness and distribution. It was found agribusiness participates with about 37\% of the GDP of the state's economy in 2012 , where the sectors with the highest relative share would be the distribution and agricultural households.

Keywords: Regional development, Input output, Policy Making.

\section{INTRODUÇÃO}

O agronegócio é o setor que mais impulsiona a economia do Brasil diante do quadro de recessão que a economia vem passando desde o ano de
2014. Embora no Brasil o agronegócio represente 23\% do PIB nacional, em algumas regiões do país essa representatividade aponta ainda uma maior participação como, por exemplo, o Estado do Mato Grosso. 
Os níveis tecnológicos alcançados pelos produtores rurais brasileiros atingiram patamares expressivos que podem ser mensurados pelo aumento da produtividade no campo e, consequentemente, da produção de grãos no país que estima-se em, aproximadamente, 200 milhões de toneladas para a safra 2015/2016 (CNA, 2014).

O agronegócio do Mato Grosso do Sul, no cenário nacional e internacional, tem posição estratégica com grande extensão de solos férteis e a constante diversificação das atividades desenvolvidas na agropecuária. Ainda, com forte participação do binômio soja-boi nos últimos 10 anos, há uma diversificação pela implantação de agroindústrias ligadas aos setores já consagrados na economia do Estado mas, incluindo também, os setores da florestas e da bioenergia.

Segundo dados da Companhia Nacional de Abastecimento (CONAB), o Estado registrou uma elevação de $113 \%$ em sua área agrícola cultivada e um aumento médio de produtividade por hectare, que nos últimos 30 anos atingiu cerca de $236 \%$ (CONAB, 2010).

Entretanto, com a diversificação e implantação da agroindústria, o setor agropecuário teve queda de $31 \%$ na participação do PIB estadual de 2002 a 2012, participando atualmente com $15 \%$ do total do PIB. Mesmo com essa queda, os setores ligados à indústria e serviços, que tiveram aumentos de participação, têm parte deste crescimento ligado aos setores agropecuários, participando em $22 \%$ e $63 \%$ a indústria e os serviços, respectivamente, no total das atividades do PIB em 2012 (IBGE, 2014a).

A forte ligação da agropecuária com os demais setores da economia tem sido reconhecida como um componente importante no processo de desenvolvimento econômico do Estado, contribuindo para a criação de renda e emprego, ao mesmo tempo que reduz a pobreza e a insegurança alimentar. Em 2012, foi o setor de desdobramentos das atividades agropecuárias que ditaram o ritmo do setor industrial principalmente: Abate de bovinos, suínos e aves, importantes na indústria de transformação; florestas englobando a expansão da silvicultura ligada a produção de papel e celulose e; produção de álcool por parte das usinas.
Além disso, a produção de álcool e de papel e celulose tem tido grande importância na geração de energia de biomassa. O objetivo deste artigo foi o de desagregar os setores ligados ao agronegócio em I) insumos para a agricultura e pecuária; II) agropecuária; III) processamento (agroindústria); IV) distribuição e serviços (agroserviços e comércio) e verificar a importância do setor para a geração de renda, emprego, tributos, comércio interestadual e internacional dentro da economia de Mato Grosso do Sul. Neste sentido, a desagregação parte dos resultados macroeconômicos da produção do setor específico para uma visão aplicada e específica do agronegócio estadual.

Esta desagregação do PIB setorizado do agronegócio se apresenta necessária com pois a correta identificação e dimensionamento do peso do setor na geração e produção de renda e riqueza permitira uma análise mais concisa, contribuindo para que os tomadores de decisão seja do setor público quanto privado, possam canalizar esforços no sentido de dar condição de que o setor possa se expandir e contribuir ainda mais na geração de renda e riqueza no Estado.

Para tanto, a desagregação dos setores com fortes ligações com o agronegócio seria realizada pela utilização da Matriz de Insumo-Produto Regional do Estado em 2012. O uso desta ferramenta para análises torna-se correta pois a matriz insumo-produto consegue descrever a relação de interdependência entre os setores e com o próprio setor sendo, portando, a mais indicada para este tipo de estudo (Guilhoto, 2011). Nesse sentido, o artigo está dividido da seguinte maneira: a seção 2 apresenta, de forma sucinta, a base de dados utilizados e a metodologia de mensuração do agronegócio; a seção 3 avalia a estrutura do agronegócio e estima os agregados do PIB do agronegócio separadamente e como um todo; finalmente, as principais conclusões obtidas no decorrer das análises são apresentadas na última seção.

\section{FUNDAMENTAÇÃO TEÓRICA}

O ponto de partida das considerações teóricas refere-se à Teoria de Insumo-Produto. Em uma visão geral, Leontief (1936) conseguiu realizar a construção de uma "fotografia" econômica da 
economia dos Estados Unidos. Nessa fotografia os setores estão relacionados entre si, proporcionando uma visão única e compreensível de como a economia funciona e de como cada setor se torna mais ou menos dependente dos outros.

O Quadro 1 mostra um exemplo de uma tabela de insumo-produto para uma economia com dois setores: dinâmica dessa economia. Essa é a visão encontrada em Isard (1951) onde a investigação desenvolve uma tabela com multiplicadores definidos, integrando os produtores de forma a mostrar as relações entre eles.

A segunda visão de tabela de insumo-produto seria um modelo mais complexo incluindo relações interindustriais, onde a produção tem muitas outras

Quadro 1 - Exemplo de uma tabela de Insumo-Produto para uma economia com dois setores. Fonte: Guilhoto (2011)

\begin{tabular}{lccccccc}
\hline & Setor 1 & Setor 2 & $\mathrm{C}$ & $\mathrm{G}$ & $\mathrm{I}$ & $\mathrm{E}$ & Total \\
\hline Setor 1 & $\mathrm{Z}_{11}$ & $\mathrm{Z}_{12}$ & $\mathrm{C}_{1}$ & $\mathrm{G}_{1}$ & $\mathrm{I}_{1}$ & $\mathrm{E}_{1}$ & $\mathrm{X}_{1}$ \\
Setor 2 & $\mathrm{Z}_{21}$ & $\mathrm{Z}_{22}$ & $\mathrm{C}_{2}$ & $\mathrm{G}_{2}$ & $\mathrm{I}_{2}$ & $\mathrm{E}_{2}$ & $\mathrm{X}_{2}$ \\
Importação & $\mathrm{M}_{1}$ & $\mathrm{M}_{2}$ & $\mathrm{M}_{\mathrm{c}}$ & $\mathrm{Mg}$ & $\mathrm{M}_{\mathrm{i}}$ & $\mathrm{T}$ & $\mathrm{T}$ \\
Impostos & $\mathrm{T}_{1}$ & $\mathrm{~T}_{2}$ & $\mathrm{~T}_{\mathrm{c}}$ & $\mathrm{Tg}$ & $\mathrm{Ti}$ & $\mathrm{T}$ & $\mathrm{W}$ \\
VA & $\mathrm{W}_{1}$ & $\mathrm{~W}_{2}$ & & & $\mathrm{I}$ & $\mathrm{E}$ & \\
\hline Total & $\mathrm{X}_{1}$ & $\mathrm{X}_{2}$ & $\mathrm{C}$ & $\mathrm{G}$ & & & \\
\hline
\end{tabular}

Onde: $Z_{\mathrm{ij}}$ é o fluxo monetário entre os setores i e j; $\mathrm{C}_{\mathrm{i}}$ é o consumo das famílias dos produtos do setor $\mathrm{i} ; \mathrm{G}_{\mathrm{i}}$ é o gasto do governo junto ao setor $\mathrm{i}$; $\mathrm{I}_{\mathrm{i}}$ é demanda por bens de investimento produzidos no setor $\mathrm{i}$; $\mathrm{E}_{\mathrm{i}}$ é o total exportado pelo setor $\mathrm{i}$; $\mathrm{X}_{\mathrm{i}}$ é o total de produção do setor $\mathrm{i}$; $\mathrm{T}_{\mathrm{i}}$ é o total de impostos indiretos líquidos pagos por i; $\mathrm{M}_{\mathrm{i}}$ é a importação realizada pelo setor i e; $W_{i}$ é o valor adicionado gerado pelo setor $i$.

No Quadro 1 é estabelecida uma igualdade entre o que está sendo vendido e comprado dentro de uma economia. Isso é possível por causa das propriedades do sistema de insumo-produto que pode ser generalizado para alguns argumentos no contexto de uma economia, seja ela nacional, regional ou local.

A definição de uma tabela de insumo-produto como um simples sistema de dupla entrada contábil, onde as transações são computadas entre os produtores, implica teórica e empiricamente, relações estabelecidas entre eles. Três percepções da tabela de insumo-produto podem ser distinguidas claramente na literatura. A primeira mostra uma visão da tabela de insumo-produto em uma análise da economia regional, projetando e analisando, o impacto de mudanças na estrutura e na relações como: economia, demografia, ambiente influenciados dentro do modelo. Essa visão tem o foco de interesse no sistema socioeconômico e menor interesse nos fatores que determinam a integração da tabela de insumo-produto. A aplicação dessa visão foi realizada por Isard e Anselin (1982), que proporcionam uma análise mais sofisticada dos sistemas econômicos regionais.

A terceira visão de tabelas de insumo-produto está na integração da parte social como um subconjunto da economia regional e da nacional. Nessa visão, um contexto nacional no qual o Sistema Nacional de Contas (SNC) e, posteriormente, a matriz de contabilidade social (SAM), seriam inseridos na análise. Esse modelo desenvolvido por Pyatt e Roe (1977), como também, outras aplicações para a SAM, tem fornecido uma base estatística de análise da geração da renda dos grupos econômicos e sociais e seus efeitos em diferentes políticas de intervenção na distribuição de renda.

Neste artigo utiliza-se a visão de Pyatt e Roe (1977) de construção de uma matriz regional a partir da estrutura da matriz nacional, estabelecendo relações e integrações entre os setores e os produtos principais da economia regional. A estrutura do modelo de matriz regional tem diferentes 
características do modelo proposto por Leontief (1951, 1953) e tem sido implementado em aplicações específicas, incluindo análises dos efeitos das economias regional sobre a economia nacional. Nessa análise, é possível extrair pelas relações de insumo-produto regional do agronegócio e quantificar suas relações, privilegiando os resultados na forma de PIB do agronegócio.

Segundo Davis e Goldberg (1957), o agronegócio é a soma total das operações de produção e distribuição de suprimentos agrícolas envolvendo: insumos, produção, armazenamento, processamento e distribuição.

De acordo com Araújo Neto e Costa (2005) e Cruz et al. (2009) essa interpretação consiste numa perspectiva sistêmica, pela qual a agropecuária é visualizada como o núcleo de um sistema econômico que se denominou Complexo Agroindustrial (CAI). Tal núcleo é integrado com setores a montante e a jusante, o que caracteriza um encadeamento intersetorial subjacente ao CAI, conforme a representação na Figura 1.

Nos estudos mais recentes sobre o CAI na economia brasileira, tem-se mostrado uma sinergia em termo de critério de classificação setorial dos segmentos fornecedores de insumos agropecuários a montante. Os estudos de Furtuoso (1998),
Nunes e Contini (2001), Furtuoso e Guilhoto (2003), Guilhotto et al. (2006) e Montoya e Finamore (2001) para a análise brasileira do agronegócio definindo uma classificação quase uniforme dos setores que compõe.

Com o uso da matriz insumo-produto para análises setoriais, o mesmo pode revelar o grau de desenvolvimento e complementariedade entre setores e de forma regional, podendo deixar em evidência o setor escolhido (Montoya, 2002).

Para o dimensionamento do agronegócio deve-se considerar a contribuição de cada segmento da sua cadeia produtiva e as inter-relações sobre aquisições e vendas para outros setores da economia. Portanto, é fundamental a construção da matriz insumo-produto, com um detalhamento das cadeias produtivas e o agregado de atividades que participam dos sistemas que constituem o agronegócio.

Com a construção da matriz insumo-produto do agronegócio em Mato Grosso do Sul pretende-se mensurar o PIB do Estado e caracterizar o agronegócio na economia regional conforme os grandes agregados que compõe o CAI para o ano de 2012. Especificamente, tem-se como objetivo estimar o PIB do agronegócio, desagregando as atividades mais importantes para a geração do montante do PIB.

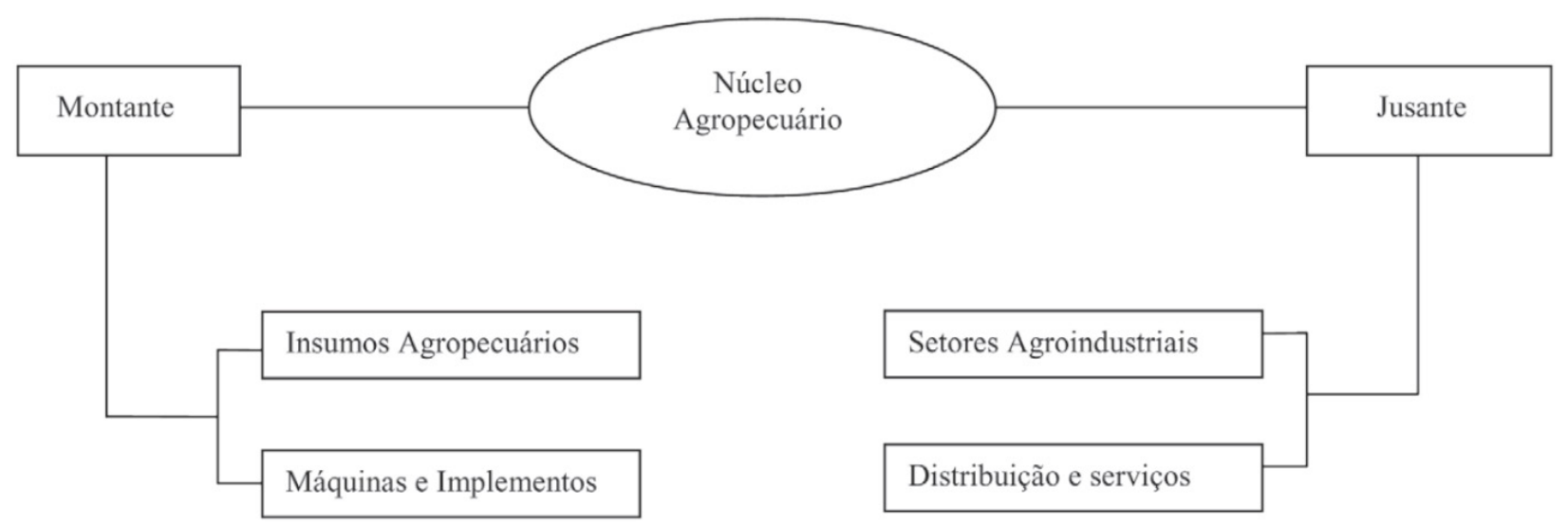

Figura 1 - Representação esquemática da agropecuária à montante e à jusante. Fonte: Araújo Neto e Costa (2005). 


\section{MATERIAL E MÉTODOS}

Para adequar a metodologia de estimativa do Produto Interno Bruto do Complexo Agroindustrial sul-matogrossense, os procedimentos usuais de contabilidade nacional praticados pelo Instituto Brasileiro de Geografia e Estatística (IBGE) foram utilizados sobre a base de dados regional. Assim, o produto do CAI representa a produção de todas as unidades produtivas de bens e serviços inter-relacionadas com a agropecuária em ligações a montante e a jusante, no ano de 2012, avaliados a preços de consumidor.

O procedimento de cálculo do PIB estadual é o mesmo praticado pelo IBGE em relação ao PIB nacional, isto é, a metodologia para o cálculo do PIB do agronegócio fundamentando-se na intensidade da interligação para trás (antes da porteira) e para frente (depois da porteira) da agropecuária. O PIB do agronegócio resulta da soma de quatro agregados principais: I) insumos para a agricultura e pecuária; II) agropecuária; III) processamento (agroindústria) e; IV) distribuição e serviços (agroserviços e comércio).

A definição de setores e produtos a serem considerados dentro do CAI do MS recai sobre as particularidades do Estado. O cálculo de valor adicionado a preços de consumidor $\left(\mathrm{VA}_{\mathrm{PC}}\right)$ é obtido pela soma do valor adicionado a preços básicos $\left(\mathrm{VA}_{\mathrm{PB}}\right)$ aos impostos indiretos líquidos de subsídios (IIL), resultando na equação (1).

$V A_{P C}=V A_{P B}+I I L$

Para o cálculo do PIB do agregado I (insumos para agricultura e pecuária), são utilizadas as informações disponíveis na tabela de transações da matriz de insumo-produto referentes aos valores dos insumos adquiridos pela agricultura e pecuária. As colunas com os valores dos insumos são multiplicadas pelos respectivos coeficientes de valor adicionado por setor i $\left(\mathrm{CVA}_{\mathrm{i}}\right)(\mathrm{i}=1, \cdots, \mathrm{n})$. Para se obter os Coeficientes do Valor Adicionado por setor $\left(\mathrm{CVA}_{\mathrm{i}}\right)$ divide-se o Valor Adicionado a Preços de Consumidor $\left(\mathrm{VA}_{\mathrm{PC}}\right)$ pela Produção do Setor $\left(\mathrm{X}_{\mathrm{i}}\right)$, equação (2).

$$
C V A_{i}=\frac{V A_{P C_{i}}}{X_{i}}
$$

Dessa forma, o problema de dupla contagem, comumente apresentado nas mensurações do PIB do agronegócio, quando se leva em consideração os valores dos insumos e não o valor adicionado efetivamente gerado na produção foi eliminado, segundo Furtuoso e Guilhotto (2003). Tem-se, na equação (3), a formulação da agregação dos valores de produção do PIB do agregado I.

$$
P I B_{I k}=\sum_{i=1}^{n} z_{i k} \times C V A_{i} \quad \mathrm{k}=1,2
$$

Onde $P I B_{\boldsymbol{k}}=$ PIB do agregado I (insumos) para agricultura $(\mathrm{k}=1)$ e pecuária $(\mathrm{k}=2) ; \mathrm{z}_{\mathrm{ik}}=$ valor total do insumo do setor $i$ para a agricultura ou pecuária; e $\mathrm{CVA}_{\mathrm{i}}=$ coeficiente de valor adicionado do setor i.

Para o agregado I total tem-se na equação (4).

$$
P I B_{I}=P I B_{I_{1}}+P I B_{I_{2}}
$$

Onde $\mathrm{PIB}_{\mathrm{I}}=\mathrm{PIB}$ do agregado I; $\mathrm{PIB}_{\mathrm{I}_{1}}=\mathrm{PIB}$ da agricultura e; $\mathrm{PIB}_{\mathrm{I}_{2}}=\mathrm{PIB}$ da pecuária.

Para o agregado II (agricultura e pecuária) consideram-se no cálculo os valores adicionados gerados pelos respectivos setores e, subtraem-se dos valores adicionados destes setores os valores que foram utilizados como insumos, mas eliminando o problema da dupla contagem, conforme a equação (5).

$$
P I B_{I I k}=V A_{P C_{k}}-\sum_{i=1}^{n} z_{i k} \times C V A_{i} \quad \mathrm{k}=1,2
$$

Onde PIB $_{\text {II }}=$ PIB do agregado II para agricultura $(\mathrm{k}=1)$ e pecuária $(\mathrm{k}=2)$; e demais variáveis descritas nas equações anteriores.

A equação (6) descreve a agregação total do agregado II.

$$
P I B_{I I}=P I B_{I I_{1}}+P I B_{I I_{2}}
$$

Onde $\mathrm{PIB}_{\mathbf{I}}=$ PIB do agregado II; $\mathrm{PIB}_{\mathbb{I}_{1}}=\mathrm{PIB}$ da agricultura e; $\mathrm{PIB}_{\mathbb{I}_{2}}=$ PIB da pecuária. 
Para a definição da composição das indústrias de base agrícola (agregado III) adotam-se vários indicadores, como: a) os principais setores demandantes de produtos agrícolas, obtido através da matriz de insumo-produto regional; b) as participações dos insumos agrícolas no consumo intermediário dos setores agroindustriais; e c) as atividades econômicas que efetuam a primeira, a segunda e a terceira transformação das matérias-primas agrícolas.

Dessa forma, os ramos industriais de base agrícola (agroindústrias) são selecionados pelas seguintes atividades no Estado: i) alimentos e bebidas; ii) produtos de madeira - exclusive móveis; iii) celulose e fabricação de papel; e iv) álcool. A equação (7), que é o somatório dos valores adicionados pelos setores agroindustriais, subtraídos dos valores adicionados dos setores que foram utilizados como insumos do agregado II, produz o PIB do agregado III.

$$
P I B_{I I l k}=\sum_{q \in k}\left(V A_{P C_{k}}-z_{q k} \times C V A_{q}\right)
$$

Onde $\mathrm{PIB}_{\text {IIIk }}=$ PIB do agregado III para agricultura $(\mathrm{k}=1)$ e pecuária $(\mathrm{k}=2)$ e; $\mathrm{z}_{\mathrm{qk}}=$ valor dos insumos da agroindústria adquirido pela agropecuária.

Para o agregado III total tem-se na equação (8) a descrição da somatória.

$$
P I B_{I I I}=P I B_{I I I_{1}}+P I B_{I I I_{2}}
$$

No caso do agregado IV, a distribuição final considera-se para fins de cálculo o valor agregado dos setores relativos ao Transporte e Armazenagem e Comércio e Serviços. Do valor total obtido destina-se ao agronegócio apenas a parcela que corresponde à participação dos produtos agropecuários e agroindustriais na demanda final de produtos. A sistemática adotada no cálculo do valor de distribuição final do agronegócio industrial pode ser representada pelas equações (9), (10) e (11).

$$
D F G-I I L_{D F}-P I_{D F}=D F D
$$

$V A T_{P C}+V A C_{P C}+V A S_{P C}=M C$

$P I B_{I V_{k}}=M C * \frac{D F_{K}+\sum_{q=1} D F_{q}}{D F D} \quad \mathrm{k}=1,2$

Onde $\mathrm{DFG}=$ Demanda Final Global; $\mathrm{IIL}_{\mathrm{DF}}=$ Impostos Indiretos Líquidos pagos pela Demanda Final; $\mathrm{PI}_{\mathrm{DF}}=$ Produtos Importados pela Demanda Final (do Brasil e Exterior); DFD = Demanda Final Doméstica; $\mathrm{VAT}_{\mathrm{PC}}=$ Valor Adicionado do Setor de Transporte a preços de consumidor; $\mathrm{VAC}_{\mathrm{PC}}=$ Valor Adicionado do Setor de Comércio a preços de consumidor; $\mathrm{VAS}_{\mathrm{PC}}=$ Valor Adicionado do Setor de Serviços a preços de consumidor; $\mathrm{MC}=$ Margens de Comercialização; $\mathrm{DF}_{\mathrm{k}}=$ Demanda Final da agricultura $(\mathrm{k}=1)$ e da pecuária $(\mathrm{k}=2) ; \mathrm{DF}_{\mathrm{q}}=$ Demanda Final dos Setores Agroindustriais; $\mathrm{PIB}_{\mathrm{IVk}}=\mathrm{PIB}$ do agregado IV para a agricultura $(\mathrm{k}=1)$ e da pecuária $(\mathrm{k}=2)$.

O PIB total do agronegócio é dado pela soma dos seus agregados, definido na equação (12),

$$
P I B_{\text {Agronegóciok }}=P I B_{I_{k}}+P I B_{I I_{k}}+P I B_{I I I_{k}}+P I B_{I V_{k}}
$$

Onde $\mathrm{PIB}_{\text {Agronegócio }_{\mathrm{k}}}=\mathrm{PIB}$ do agronegócio para a agricultura $(\mathrm{k}=1)$ e da pecuária $(\mathrm{k}=2)$.

O PIB do total do agronegócio, representado pela soma dos PIBs da agricultura e da pecuária, é dado pela equação (13).

$$
P I B_{\text {Agronegócio }}=P I B_{\text {Agronegócio }_{1}}+P I B_{\text {Agronegócio }_{2}}
$$

A metodologia descrita anteriormente pode ser vista de uma forma esquemática na Figura 2 que apresenta o processo de obtenção do PIB do agronegócio. Observa-se então que o PIB do agronegócio pode ser obtido tanto pela soma ponderada do PIB dos agregados como pela soma ponderada dos PIBs da agricultura e da pecuária. 


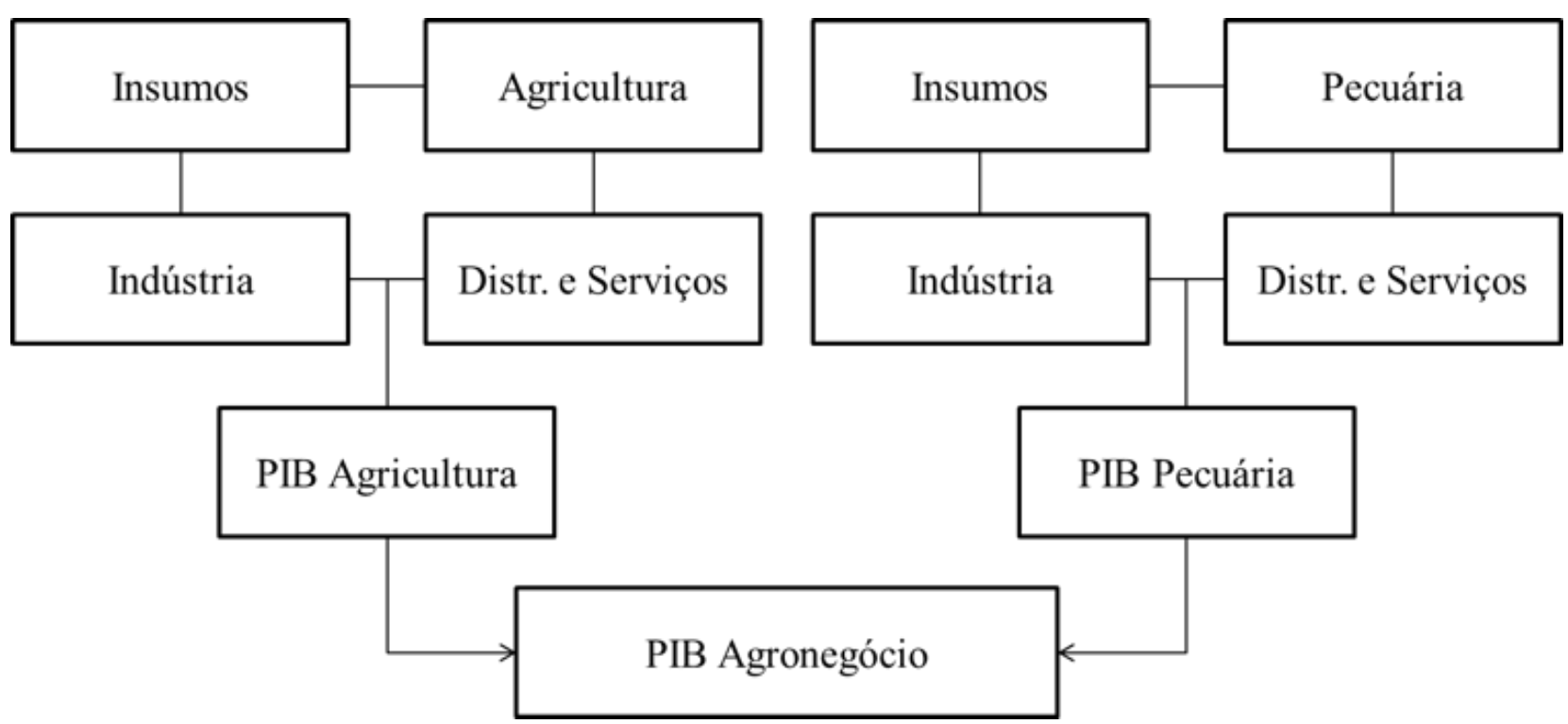

Figure 2 - Representação esquemática do processo de obtenção do PIB do agronegócio. Fonte: Adaptado de Guilhoto et al. (2006).

As bases de dados utilizadas no cálculo do PIB do agronegócio estão contidas nas pesquisas de contas nacionais (IBGE, 2014a) e regionais (IBGE, 2014a) para realizar a desagregação dos setores do agronegócio que não são contempladas nas pesquisas do PIB. Seria possível pela metodologia descrita anteriormente do CAI e com a utilização da matriz de insumo-produto regional (MIP), elaborada com uma abertura de 36 setores de atividade econômica e de 45 produtos. Esse grau de abertura setorial e de produtos possui uma compatibilização com a estrutura setorial e de produtos da MIP nacional, calculada pelo IBGE para 56 setores da economia nacional (IBGE, 2010). O modelo base para a desagregação segue o exposto simplificado no quadro 1 da seção fundamentação teórica.

Na versão 2012, a MIP-MS tem as relações setoriais da atividade agropecuária desmembradas em dois setores: (a) agricultura, silvicultura e extração vegetal; e (b) pecuária e pesca. Do mesmo modo, sua elaboração seguiu a metodologia nacional a partir das tabelas de recursos e usos 2012 do MS construídas por estimativas através das informações do Valor Adicionado por setor de atividade, obtido pelas pesquisas: Contas Regionais do Brasil 2012 (IBGE, 2014a), Pesquisa Agrícola Municipal 2012 (IBGE 2014b), Pesquisa da Pecuária Municipal 2012 (IBGE, 2014c), Pesquisa Anual da Extrativa Vegetal 2014 (IBGE, 2014d), Pesquisa Anual da Indústria da Construção 2012 (IBGE, 2014e), Pesquisa Anual de Serviços 2012 (IBGE, 2014f), Pesquisa Anual do Comércio 2012 (IBGE, 2014g) e Pesquisa Industrial Anual 2012 (IBGE, 2014h).

Os dados relativos ao comércio com o resto do Brasil e impostos estaduais, foram obtidos junto a Secretaria de Estado da Fazenda (SEFAZ - MS). Já em relação a comércio internacional e impostos federais junto a Secretaria de Comércio Exterior (SECEX) e Receita Federal (RF).

\section{RESULTADOS E DISCUSSÃO}

Os setores da economia do Estado possuem fortes relações com os setores da Agropecuária tanto em termos de participação direta no PIB, como a montante os insumos e, a jusante, com a indústria de transformação, comércio e serviços. Para mensurar esses efeitos primeiramente tem-se em consideração os valores adicionados dos grandes setores do Estado.

O agronegócio de MS, medido a preços básicos, chegou a responder por cerca de $37 \%$ do PIB estadual em 2012. A estrutura para elaboração do PIB do agronegócio a preços de consumidor está apresentada no Quadro 2. 
Quadro 2 - Estrutura para agregação no PIB do estado de MS em 2012 a preços de consumidor. Fonte: Dados da pesquisa

\begin{tabular}{lccc}
\hline Agregados & $\begin{array}{c}\text { Valor agregado } \\
\text { a preços ao } \\
\text { consumidor } \\
\text { (em R\$ milhões) }\end{array}$ & $\begin{array}{c}\text { Participação } \\
\text { relativa dos } \\
\text { agregados no PIB } \\
\text { estadual (\%) }\end{array}$ & $\begin{array}{c}\text { Participação } \\
\text { relativa dos } \\
\text { agregados no PIB } \\
\text { do agronegócio } \\
\text { (\%) }\end{array}$ \\
\hline Agregado I & $1.394,00$ & 2,56 & 6,99 \\
Agregado II & $7.005,00$ & 12,86 & 35,13 \\
Agregado III & $4.206,00$ & 7,72 & 21,09 \\
Agregado IV & $7.337,00$ & 12,44 & 36,79 \\
\hline Total & $19.942,00$ & 36,61 & 100,00 \\
\hline
\end{tabular}

Observe, do Quadro 2, com relação ao agregado IV, que correspondente à distribuição, os valores são mais expressivos, sendo o principal componente do PIB do agronegócio, com 36,79\% de participação.

Embora grande parte dos insumos seja comprada fora do Estado e outra no exterior, a parcela comprada no MS representa parte significativa dessa compra. O Quadro 3 apresenta a estrutura dos insumos do MS em 2012, a preços de consumidor.

Quadro 3 - A estrutura dos insumos no MS em 2012 a preços de consumidor. Fonte: Dados da pesquisa

\begin{tabular}{lccc}
\hline $\begin{array}{c}\text { Insumos } \\
\text { por setor de } \\
\text { atividade }\end{array}$ & $\begin{array}{c}\text { Valor Agregado } \\
\text { a preços de } \\
\text { consumidor } \\
\text { (em R\$ milhões) }\end{array}$ & $\begin{array}{c}\text { Participação } \\
\text { relativa no } \\
\text { agregado I (\%) }\end{array}$ & $\begin{array}{c}\text { Participação } \\
\text { relativa dos } \\
\text { agregados no PIB } \\
\text { do agronegócio } \\
\text { (\%) }\end{array}$ \\
\hline Agricultura & 639 & 45,81 & 3,20 \\
Pecuária & 756 & 54,19 & 3,79 \\
\hline Total & 1.394 & 100,00 & 6,99 \\
\hline
\end{tabular}

Dos Quadros 1 e 2 conclui-se que o agregado I, que corresponde aos insumos a montante, relacionados com o agronegócio, os resultados apontam para uma participação de cerca 6,99\% no PIB do agronegócio, sendo que a participação dos insumos da pecuária é de 3,79\% e, o da agricultura, de 3,20\%. Ainda, com relação aos valores referentes aos insumos, a sua participação na pecuária, que são comprados no Estado, é maior do que o da agricultura, com $54,19 \%$ contra $45,81 \%$, respectivamente.

O agregado II, ou produtos da agropecuária, está fortemente vinculada aos setores urbanos e, portanto, interconectada ao resto da economia, uma vez que, do produto total da agropecuária, cerca de $42 \%$ são gerados no campo e $58 \%$ são gerados nos setores urbanos da economia do Estado (agregados III e IV). o Quadro 4 apresenta a estrutura da agropecuária no MS em 2012 a preços de consumidor.

Quadro 4 - A estrutura da agropecuária no estado de MS em 2012 a preços de consumidor. Fonte: Dados da pesquisa.

\begin{tabular}{lccc}
\hline & Valor Agregado a & Participação \\
$\begin{array}{c}\text { Setores da } \\
\text { agropecuária }\end{array}$ & $\begin{array}{c}\text { preços de } \\
\text { consumidor } \\
\text { (em R\$ milhões) }\end{array}$ & $\begin{array}{c}\text { Participação } \\
\text { relativa no } \\
\text { agregado II (\%) }\end{array}$ & $\begin{array}{c}\text { relativa dos } \\
\text { agregados no PIB } \\
\text { do agronegócio } \\
\text { (\%) }\end{array}$ \\
\hline Agricultura & 3.727 & 53,20 & 18,69 \\
Pecuária & 3.279 & 46,80 & 16,44 \\
\hline Total & 7.005 & 100,00 & 35,13 \\
\hline
\end{tabular}

No agregado II foi possível verificar a participação da agricultura e da pecuária separadamente. A agricultura tem uma participação maior na geração de valor agregado no Estado do que a pecuária, 53,20\% contra $46,80 \%$, respectivamente. Com relação a participação relativa no agregado II no total do PIB do agronegócio chega a 35\%, sendo o segundo maior agregado ficando atrás apenas da distribuição, que participava com 36,79\%. O Quadro 5 apresenta a estrutura da agroindústria no MS em 2012 a preços de consumidor.

Quadro 5 - A estrutura da agroindústria no estado de MS em 2012 a preços de consumidor. Fonte: Dados da pesquisa.

\begin{tabular}{lccc}
\hline $\begin{array}{c}\text { Subsetores da } \\
\text { indústria de } \\
\text { transformação }\end{array}$ & $\begin{array}{c}\text { Valor Agregado } \\
\text { a preços de } \\
\text { consumidor }\end{array}$ & $\begin{array}{c}\text { Participação } \\
\text { relativa no } \\
\text { agregado III (\%) }\end{array}$ & $\begin{array}{c}\text { Participação } \\
\text { relativa dos } \\
\text { agregados no PIB } \\
\text { do agronegócio } \\
\text { (em) }\end{array}$ \\
\hline $\begin{array}{c}\text { Alimentos } \\
\text { e Bebidas }\end{array}$ & 2.143 & 50,95 & 10,75 \\
$\begin{array}{c}\text { Têxtil } \\
\text { Produtos }\end{array}$ & 227 & 5,39 & 1,14 \\
$\begin{array}{c}\text { de madeira } \\
\text { Celulose } \\
\text { e papel }\end{array}$ & 42 & 0,99 & 0,21 \\
Álcool & 602 & 14,31 & 3,02 \\
Química & 944 & 22,45 & 4,74 \\
\hline Total & 248 & 5,90 & 1,24 \\
\hline
\end{tabular}


Do Quadro 5 observa-se que o agregado III, a agroindústria, corresponde a $21,09 \%$ do PIB do agronegócio. Os subsetores que apresentam maior participação seria o: Alimentos e Bebidas, com cerca de 51\%, seguida pela Produção de Álcool, com 22,45\% e Celulose e Papel, 14,31\%.

Do Quadro 6 observa-se que o comércio foi o principal componente, respondendo com $34,16 \%$ do agregado IV, além de representar 12,57\% dentro do PIB do agronegócio. Historicamente, os setores ligados ao comércio representam grande parte do PIB estadual, sendo que em 2012 foi cerca de 14\% do PIB estadual.

Entretanto, a participação do comércio do agronegócio na economia de MS representa 34\% do PIB do comércio, ou seja, caso haja uma queda no PIB do agronegócio, cerca de $34 \%$ do comércio seria afetado por essa queda.

Comportamento semelhante apresenta os serviços que, em 2012, participa com cerca de 26\% do PIB estadual. Com relação à parcela relativa dos serviços do agronegócio, essa representa 9\% no PIB estadual, ou seja, caso haja uma queda no PIB

Quadro 6 - A estrutura da Distribuição no Estado de MS em 2012 a preços de consumidor. Fonte: Dados da pesquisa

\begin{tabular}{cccc}
\hline $\begin{array}{c}\text { Subsetores da } \\
\text { Distribuição }\end{array}$ & $\begin{array}{c}\text { Valor Agregado } \\
\text { a preços de } \\
\text { consumidor } \\
\text { (em R\$ milhões) }\end{array}$ & $\begin{array}{c}\text { Participação } \\
\text { relativa no } \\
\text { agregado IV (\%) }\end{array}$ & $\begin{array}{c}\text { Participação } \\
\text { relativa dos } \\
\text { agregados } \\
\text { no PIB do } \\
\text { agronegócio (\%) }\end{array}$ \\
\hline $\begin{array}{c}\text { Comércio } \\
\text { Transportes e } \\
\text { armazenagem }\end{array}$ & 2.506 & 34,16 & 12,57 \\
$\begin{array}{c}\text { Serviços de } \\
\text { informação }\end{array}$ & 972 & 13,24 & 4,87 \\
$\begin{array}{c}\text { Intermediação } \\
\text { financeira }\end{array}$ & 658 & 6,24 & 2,30 \\
$\begin{array}{c}\text { Atividades } \\
\text { imobiliárias }\end{array}$ & 1.120 & 9,06 & 3,33 \\
$\begin{array}{c}\text { Alojamento e } \\
\text { alimentação }\end{array}$ & 272 & 15,27 & 5,62 \\
$\begin{array}{c}\text { Serviços } \\
\text { prestados às } \\
\text { empresas }\end{array}$ & 546 & 3,71 & 1,37 \\
$\begin{array}{c}\text { Educação } \\
\text { e saúde } \\
\text { mercantil }\end{array}$ & 240 & 7,44 & 2,74 \\
$\begin{array}{c}\text { Outros Serviços } \\
\text { Total }\end{array}$ & 557 & 3,28 & 1,21 \\
\hline
\end{tabular}

do agronegócio, em cerca de $9 \%$, os serviços da economia estadual seriam afetados por essa queda.

O transporte e armazenagem, embora sejam o terceiro em termos de participação no agregado IV, possui grande importância dentro dos custos do agronegócio e tem a característica de ser praticamente a sua totalidade fornecida pela própria economia estadual, diferente dos insumos, indústria e demais subsetores da distribuição.

Os resultados da desagregação do PIB do agronegócio do MS demonstram que este setor possui relativo poder de encadeamento na economia sul mato-grossense sendo que, este encadeamento causa externalidades positivas e negativas. Positivas no sentido de que o agronegócio pode contribuir para o aumento da geração de renda e riqueza e negativo pois quando o setor está em ritmo menor de produção, os demais setores recebem uma redução do efeito indutor do agronegócio.

\section{CONCLUSÕES}

Levando em consideração a importância do estado de MS pelo seu setor agropecuário, com fortes influências para a explicação dos desempenhos dos setores urbanos, foi possível verificar o grau de associação entre estes pela aplicação da metodologia do PIB do agronegócio. A mensuração do PIB do agronegócio do MS permitiu a realização de comparações entre os setores da economia do MS e de seus agregados na economia regional, para o ano de 2012, verificando quais são mais ou menos dependentes das atividades do agronegócio e a relação do peso de cada componente na sua estrutura econômica do Estado.

A natureza dessas relações mostra a importância dos setores ligados à agropecuária, tanto a jusante como a montante, e a sua importância para a geração do PIB do agronegócio e do PIB da economia do MS em 2012.

Sendo assim, torna-se evidente que o setor possui capacidade de afetar os níveis de crescimento e desenvolvimento regional, contudo, quando de uma desaceleração no ritmo de produção, este causa prejuízos em sobremaneira a outros setores. Neste caso, o setor de agronegócios pode ser considerado 
como uma espécie de articulador entre os demais setores, atuando ainda de maneira complementar.

Os avanços de produtiva podem ser interpretados no sentido de terem contribuído para o avanço do setor, contudo destaca-se a necessária continuidade de investimentos para que o setor possa conseguir crescer e gerar externalidades positivas sobre os demais setores.

\section{REFERÊNCIAS BIBLIOGRÁFICAS}

Araújo Neto, D.L. \& Costa, E.F. (2005) - Dimensionamento do PIB do agronegócio em Pernambuco. Revista de Economia e Sociologia Rural, vol. 43, n. 4, p. 725-757. http://dx.doi.org/10.1590/S0103-20032005000400006

CNA (2014) -Balanço 2014 e Perspectivas 2015 para o Agronegócio brasileiro. Brasília: Confederação de Agricultura e Pecuária do Brasil. 141 p. [cit. 2015.03.19]. http://canaldoprodutor.com.br/revista/balanco_2014/index.html

CONAB (2010) - Acompanhamento de safra brasileira: grãos, quarto levantamento, janeiro 2010. Companhia Nacional de Abastecimento. Brasília: Conab.

Cruz, A.C.; Teixeira, E.C. \& Gomes, M.F.M. (2009) - O PIB do agronegócio no estado de Minas Gerais: uma análise insumo-produto. Revista Brasileira de Economia e Sociologia Rural, vol. 47, n. 4, p. 805-830. http:// dx.doi.org/10.1590/S0103-20032009000400001

Davis, J. \& Goldberg, R. (1957) - A concept of agribusiness. Boston: Harvard University Press.

Furtuoso, M.C.O. (1998) - O produto interno bruto do complexo agroindustrial brasileiro. 221 p. Tese (Doutorado) - Universidade de São Paulo, São Paulo.

Furtuoso, M.C.O. \& Guilhoto, J.J.M. (2003) - Estimativa e mensuração do produto interno bruto do agronegócio da economia brasileira - 1994 a 2000. Revista Brasileira de Economia e Sociologia Rural, vol. 41, n. 4, p. 803-827. http://dx.doi.org/10.1590/S0103-20032003000400005

Guilhoto, J.J.M.; Silveira, F.G.; Ichihara, S.M. \& Azzoni, C.R. (2006) - A importância do agronegócio familiar no Brasil. Revista Brasileira de Economia e Sociologia Rural, vol. 44, n. 3, p. 355-382. http://dx.doi.org/10.1590/ S0103-20032006000300002

Guilhoto, J.J.M. (2011) - Análise de Insumo-Produto: Teoria e Fundamentos. MPRA Paper 32566, University Library of Munich, Germany.

IBGE (2010) - Matriz de insumo-produto do Brasil. Rio de Janeiro: IBGE.

IBGE (2014a) - Produção Agrícola Municipal - PAM. 2002-2012. Rio de Janeiro.

IBGE (2014b) - Pesquisa da Pecuária Municipal - PPM. 2002-2012. Rio de Janeiro.

IBGE (2014c) - Pesquisa Anual da Extração Vegetal - PEVS 2002-2012. Rio de Janeiro.

IBGE (2014d) - Pesquisa Anual da Indústria da Construção 2012 - PAIC Rio de Janeiro.

IBGE (2014e) - Pesquisa Anual de Serviços 2012 - PAS Rio de Janeiro.

IBGE (2014f) - Pesquisa Anual do Comércio 2012 - PAC. Rio de Janeiro.

IBGE (2014g) - Pesquisa Industrial Anual 2012 - PIA Rio de Janeiro.

IBGE (2014h) - Sistema de Contas Nacionais do Brasil. Rio de Janeiro: IBGE.

Isard, W. (1951) - Interregional and regional input-output analysis: a model of a space economy. Review of Economics and Statistics, vol. 33, n. 4, p. 318-328.

Isard, W. \& Anselin, L. (1982) - Integration of multiregional models for policy analysis. Environment and Planning, vol. 14, n. 3, p. 359-376. https://doi.org/10.1068/a140359

Leontief, W. (1936) - Quantitative Input and Output Relations in the Economic System of the United States. The Review of Economic Statistics, vol. 18, n. 3, p. 105-125.

Leontief, W. (1951) - The Structure of American Economy 1919-1939: An Empirical Application of Equilibrium Analysis. Cambridge: Harvard University Press.

Leontief, W. (1953) - Studies in the Structure of the American Economy. New York: Oxford University Press.

Montoya, M.A. (2002) - O agronegócio no mercosul: dimensão econômica, desenvolvimento industrial e interdependência estrutural na Argentina, Brasil, Chile e Uruguai. Revista Brasileira de Economia, vol. 56, n. 4, p. 605-660. http://dx.doi.org/10.1590/\$0034-71402002000400004 
Montoya, M.A. \& Finamore, E.B. (2001) - Padrões de crescimento do agronegócio brasileiro no período de 1985 a 1995. In: XXXIX Congresso Brasileiro de Economia e Sociologia Rural, Anais, Recife.

Nunes, E.P. \& Contini, E. (2001) - Complexo Agroindustrial Brasileiro: Caracterização de Dimensionamento. Brasília: Associação Brasileira de Agrobusiness.

Pyatt, G. \& Roe, A. (1997) - Social accounting form development planning: with special reference to Sri Lanka. Cambridge: Cambridge University Press. 